\title{
Correlation between equatorial Kelvin waves and the occurrence of extremely thin ice clouds at the tropical tropopause
}

\author{
F. Immler ${ }^{1, *}$, K. Krüger ${ }^{2}$, M. Fujiwara ${ }^{3}$, G. $\operatorname{Verver}^{4}$, M. Rex ${ }^{5}$, and O. Schrems ${ }^{1}$ \\ ${ }^{1}$ Alfred Wegener Institute for Polar and Marine Research, Bremerhaven, Germany \\ ${ }^{2}$ IFM-GEOMAR, Kiel, Germany \\ ${ }^{3}$ Hokkaido University, Faculty of Environmental Earth Science, Japan \\ ${ }^{4}$ Royal Netherlands Meteorological Institute (KNMI), De Bilt, The Netherlands \\ ${ }^{5}$ Alfred Wegener Institute for Polar and Marine Research, Potsdam, Germany \\ * now at: Richard Aßmann Observatory, Lindenberg, German Meteorological Service (DWD), Germany
}

Received: 7 December 2007 - Published in Atmos. Chem. Phys. Discuss.: 13 February 2008

Revised: 3 July 2008 - Accepted: 3 July 2008 - Published: 25 July 2008

\begin{abstract}
A number of field-campaigns in the tropics have been conducted in recent years with two different LIDAR systems at Paramaribo $\left(5.8^{\circ} \mathrm{N}, 55.2^{\circ} \mathrm{W}\right)$, Suriname. The lidars detect particles in the atmosphere with high vertical and temporal resolution and are capable of detecting extremely thin cloud layers which frequently occur in the tropical tropopause layer (TTL). Radiosonde as well as operational ECMWF analysis showed that equatorial Kelvin waves propagated in the TTL and greatly modulated its temperature structure. We found a clear correlation between the temperature anomalies introduced by these waves and the occurrence of thin cirrus in the TTL. In particular we found that extremely thin ice clouds form regularly where cold anomalies shift the tropopause to high altitudes. These findings suggest an influence of Kelvin wave activity on the dehydration in the TTL and thus on the global stratospheric water vapour concentration.
\end{abstract}

\section{Introduction}

The tropical tropopause layer (TTL) is the layer between the level of zero net radiative heating which is found typically around $15 \mathrm{~km}$ and the cold point tropopause (CPT) at 17 to $18 \mathrm{~km}$. This layer is characterized by slow ascent and forms the source region for the stratospheric Brewer-Dobson circulation. Thin laminar ice clouds are frequently observed in the

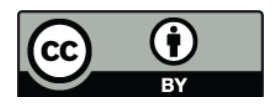

Correspondence to: F. Immler (franz.immler@dwd.de)
TTL (e.g. Winker and Trepte, 1998; Peter et al., 2003; Immler and Schrems, 2002). The way these clouds form and their ability to dehydrate the ascending air are of crucial importance for the water vapour budget of the stratosphere. While formation of clouds by direct injection from convective systems into the TTL will most likely moisten the air by evaporation of the particles (Nielsen et al., 2007), in situ formation of clouds in slowly ascending air will almost always lead to dehydration (Jensen and Pfister, 2004).

On the basis of observational data obtained at Paramaribo $\left(5.8^{\circ} \mathrm{N}, 55.2^{\circ} \mathrm{W}\right)$, Suriname we showed recently that cirrus clouds form in situ and effectively dehydrate the air as it ascends to the stratosphere (Immler et al., 2007, I07 hereafter). In accordance to modeling studies presented by Bonazzola and Haynes (2004); Jensen and Pfister (2004); Fueglistaler et al. (2005), our observations suggest that air is dried to the saturation vapour pressure of the minimum temperature that the air parcel experiences on its way to the stratosphere.

Boehm and Verlinde (2000) showed that the temperature at the tropical tropopause is significantly influenced by equatorial Kelvin waves and that the occurrence of cirrus in the upper tropical troposphere is related to the cold anomalies of these waves. Based on observations by a micropulse lidar (MPL) Boehm and Verlinde (2000) found that cirrus clouds occur primarily around $15-16 \mathrm{~km}$ and below and thus assumed that at higher altitudes moisture is not sufficient to form clouds. Furthermore, in a detailed analysis of data from the same instrument Comstock et al. (2002) demonstrated that cirrus occurrence at altitudes above $15 \mathrm{~km}$ do not coincide with negative temperature anomalies.

Published by Copernicus Publications on behalf of the European Geosciences Union. 
Equatorial Kelvin waves are large-scale disturbances that are excited by convective clusters in the troposphere and propagate along the equator to the stratosphere. They are characterized by temperature and zonal wind anomalies that propagate eastward and are limited to low latitudes. The temperature anomalies lead the associated zonal wind anomalies by a quarter cycle (Parker, 1973). There is no meridional wind component. Note that the group velocity, i.e. the energy of these waves, propagates upward, while, from a single point observation, the warm and cold phases appear to propagate downwards.

During an aircraft campaign in the Indian ocean Peter et al. (2003) observed extremely thin ice clouds near the tropical tropopause "which can neither be observed by ground-based lidar nor by the pilot of the high-flying aircraft". They suggest that these clouds are sustained by a subtle balance between up-welling of the air and sedimentation of the ice particles (Luo et al., 2003).

In September-October 2004 and in October 2006, we have conducted field campaigns at Paramaribo, Suriname with high performance ground-based lidar systems which are indeed capable of detecting extremely thin ice clouds with optical depths of $10^{-3}$ and below (I07). Based on these observations we demonstrate a strong correlation between the cold phase of Kelvin waves and the occurrence of extremely thin ice clouds at the tropical tropopause that was not observed by Boehm and Verlinde (2000) and Comstock et al. (2002). Since the extremely thin tropical cirri (ETTCi) in the cold phase of Kelvin waves were the last dehydration event that the air encountered before entering the stratosphere, we provide evidence that Kelvin waves work like a "dehydration pump" which dries the lowermost tropical stratosphere (Fujiwara et al., 2001).

\section{Observational methods}

In the frame of the European project STAR (Support for Tropical Atmospheric Research), the Mobile Aerosol Raman Lidar (MARL) was set up at the meteorological service of Suriname at Paramaribo in September 2004 and operated from 27 September 2004 to 16 December 2004 (the STAR period, hereafter) which corresponds to the local long dry season. Further campaigns followed in the short spring dry season of 2005 and 2006. In September 2006, MARL was replaced by the newly built Compact Cloud and Aerosol Lidar (ComCAL) (Immler et al., 2006). The ComCAL performs TTL cirrus observation from 19 September to 29 November 2006 (the ACLIT (Aerosol and Cloud measurements by LIdar in the Tropics) period, hereafter). While the ComCAL system was operated during day and night, the MARL was not operated between 09:00 and 16:00 local time because of its very high sensitivity and too intense background light. Both lidar systems are capable of detecting extremely thin tropical cirrus clouds near the tropopause. Further details on the lidar data analysis and cloud detection methods are found in $\mathrm{I} 07$.

Information on the meteorological conditions in the TTL were obtained by special daily Vaisala-RS80 radiosoundings at Paramaribo during the STAR period. During the ACLIT campaign, only 2-3 radiosondes were launched per week, which is insufficient to resolve Kelvin waves properly. Therefore we use the high vertical resolution dataset (on model levels) of the operational analysis from the European Centre for Medium range Weather Forecasts (opECMWF).

In I07, a newly developed trajectory code (the so-called AWI trajectory code) was discussed which uses ECMWF horizontal winds and calculates vertical velocities explicitly from radiative heating rates in the TTL and the stratosphere (Krüger et al., 2008). It was shown that it is very useful for investigating transport processes in the upper part of the TTL. This trajectory model is used here as well.

\section{Results and discussion}

Figures 1a and 3a show cloud observations by the MARL and ComCAL lidar systems during September-October 2004 and October 2006, respectively. Cirrus in the uppermost troposphere was ubiquitous. What is striking is the downward trend of the cloud top heights which seem to descend with time on a scale of several days before new clouds appear at higher altitudes. This behavior indicates the influence of synoptic-scale disturbances on the cloud occurrence.

Figure $1 \mathrm{~b}$ shows temperature anomalies retrieved from radiosonde data. These were calculated using the mean temperature profile of the period (Fig. 5a, dashed line). This compilation illustrates downward propagating warm and cold anomalies with a periodicity of 4 to 7 days (3-4 wave cycles in 19 days) that occur in the TTL and the lower stratosphere, across the cold point tropopause (dashed red line). The waves extend approximately down to the level of the upper tropospheric inversion (UTI) which is a weak inversion layer that is regularly found in tropical temperature profiles approximately $1-2 \mathrm{~km}$ below the temperature minimum and marks the lower boundary of the TTL (Immler and Schrems, 2002; Fujiwara et al., 2003).

In order to prove that the observed temperature anomalies are related to Kelvin waves Fig. 2 shows longitude-time distributions of the anomalies of the temperature and zonal and meridional wind components at $6^{\circ} \mathrm{N}$ at about $100 \mathrm{hPa}$ retrieved from the opECMWF data. We see that cold anomalies reach Paramaribo at $-55.2^{\circ}$ (dashed line) on 27-30 September (I), 3-6 October (II), and 12-14 October (III) (Fig. 2a). These eastward moving large-scale waves are the primary disturbance that cause the "large-scale" cirrus formation in Fig. 1a marked by the arrows I to III. Another cold anomaly (IIa) clearly discernible from the Radiosonde data in Fig. 1 does not appear in Fig. 2a. This is because this anomaly did not influence the $100 \mathrm{hPa}$ level significantly. Therefore, 


\section{a $\log$ (backscatter ratio)}
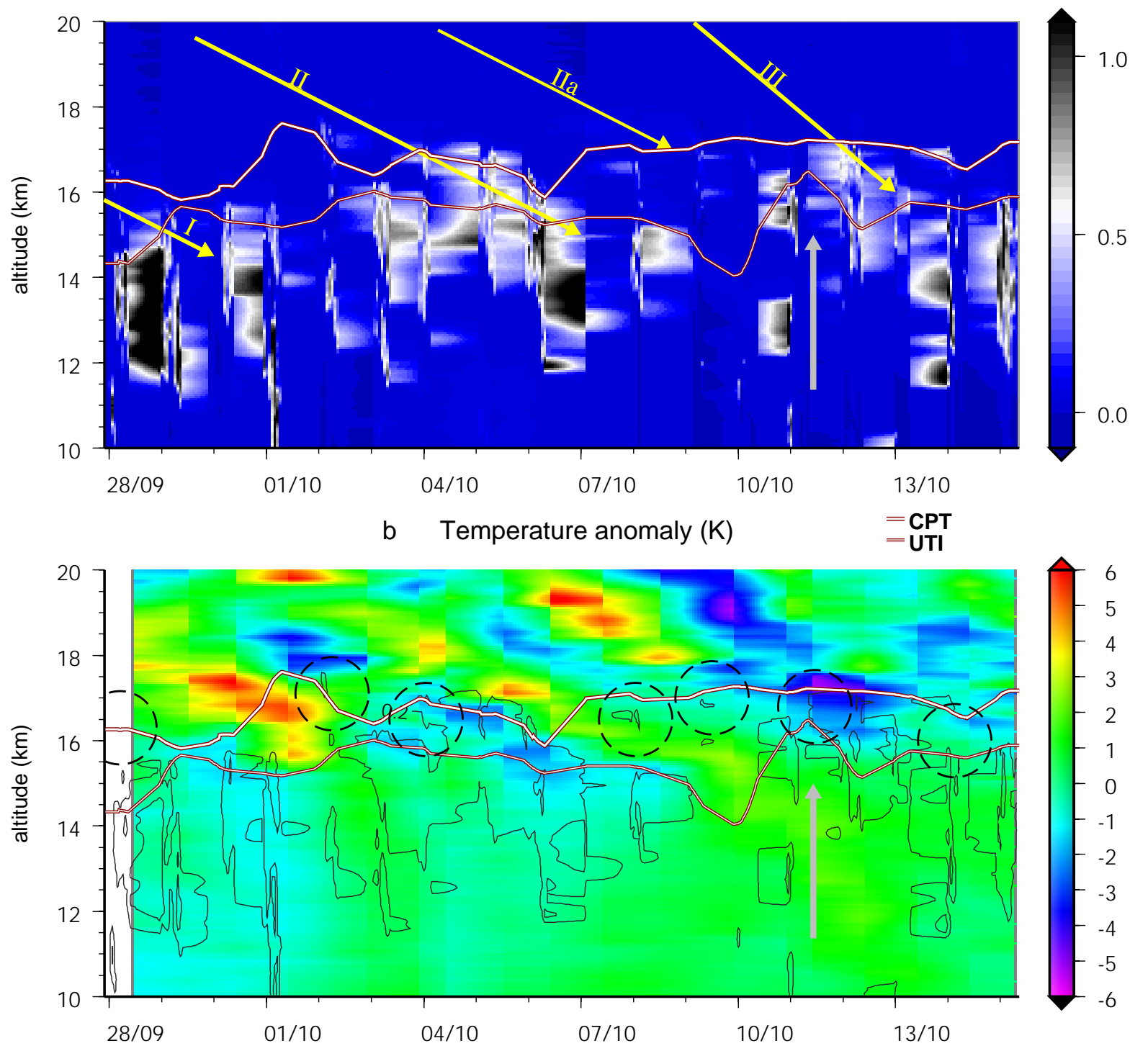

day

Fig. 1. (a) Lidar observations of cirrus clouds at Paramaribo from 27 September to 15 October 2004. Plotted is the logarithm of the backscatter ratio $R$ (i.e. observed total backscatter versus calculated pure molecular backscatter) as a function of time and altitude. Values greater than 0.25 indicate the presence of clouds. (b) Temperature anomalies calculated from radiosonde data during the same period as in (a). The thick red-shaded white lines for both panels show the location of the cold point tropopause (CPT), and the thinner lines show the location of the upper tropospheric inversion (UTI). Slanted arrows in the upper panel indicate the major cold anomalies observed in the lower panel. Black circles in (b) highlight extremely thin cirrus observed at the CPT. The contour lines in (b) indicate the cloud boundaries defined by $\ln R=0.25$. The vertical gray arrow in (b) corresponds to the case shown in Fig. 5 .

this anomaly is not associated with large scale cirrus formation. The large-scale waves which caused cirrus formation have significant temperature $(T)$ and zonal wind $(U)$ components (Fig. 2b), but do not have meridional wind $(V)$ components (Fig. 2c). The zonal phase speed is about $18 \mathrm{~m} / \mathrm{s}$ (280 degree/20 days) and the period is 7-9 days. The nega- tive $T$ anomaly leads negative $U$ anomaly by about a quarter wavelength (i.e. the negative $T$ anomaly locates to the east of negative $U$ anomaly, Fig. 2b). We have confirmed that the wave parameters reasonably satisfy the dispersion relation of Kelvin waves (Parker, 1973). Therefore, we interpret the observed waves that cause large-scale cirrus cloud formation as 

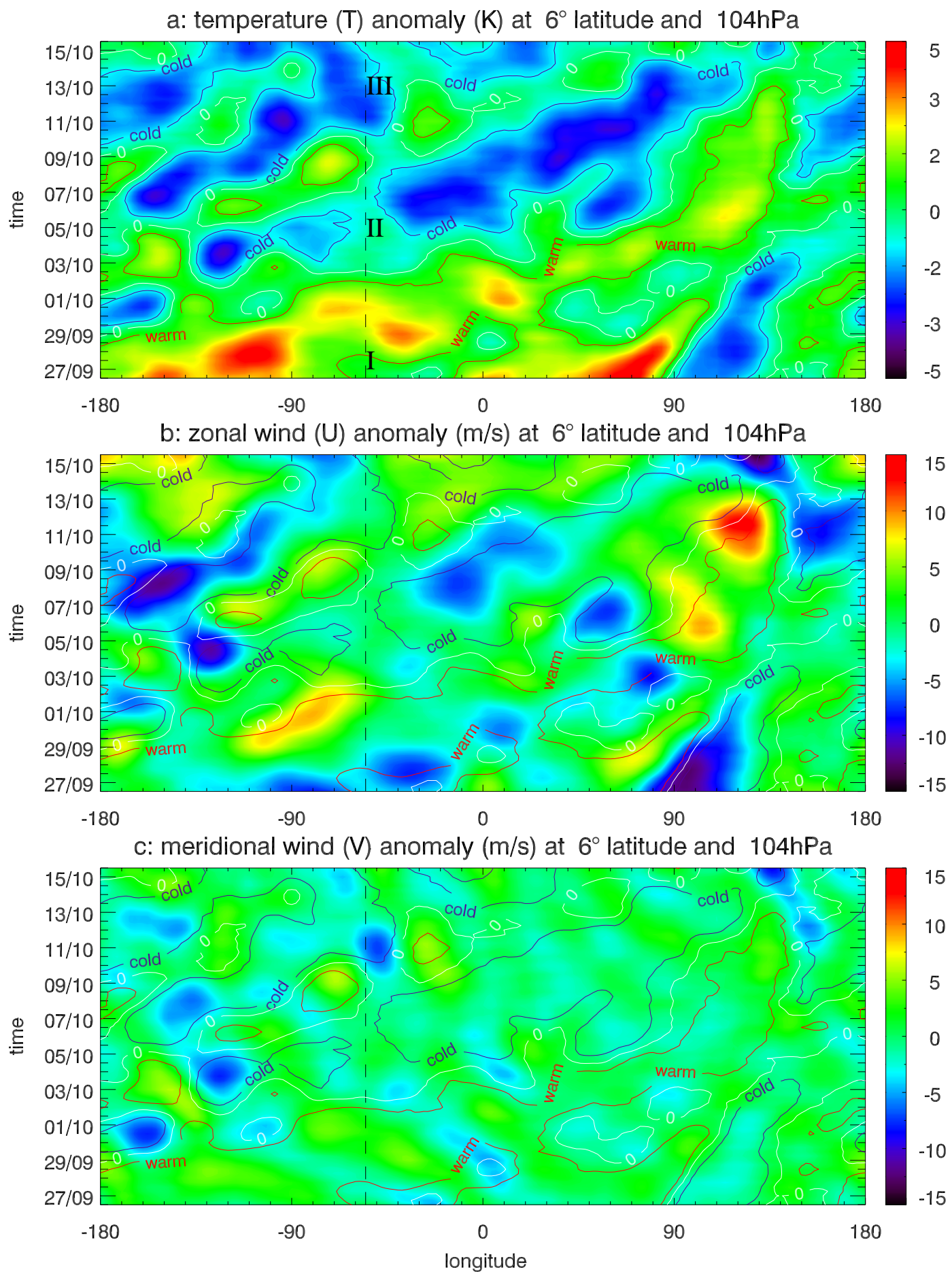

Fig. 2. Time-longitude distribution of the temporal anomalies (difference of the actual value with the mean value at the location over the entire time period) of the temperature, the zonal $(U)$ and meridional $(V)$ wind at $6^{\circ} \mathrm{N}$ and $104 \mathrm{hPa}$ (model level \#35) retrieved from the opECMWF data for the STAR period (27 September 2004 to 16 October 2004). The plots are smoothed with a boxcar average over $48 \mathrm{~h}$ and $16^{\circ}$ longitude in order to remove the diurnal variability. The contour lines in all panels mark the $-1.5 \mathrm{~K}$ (blue), 0 (white) and $+1.5 \mathrm{~K}$ (red) temperature anomalies. 
a $\log$ (backscatter ratio)
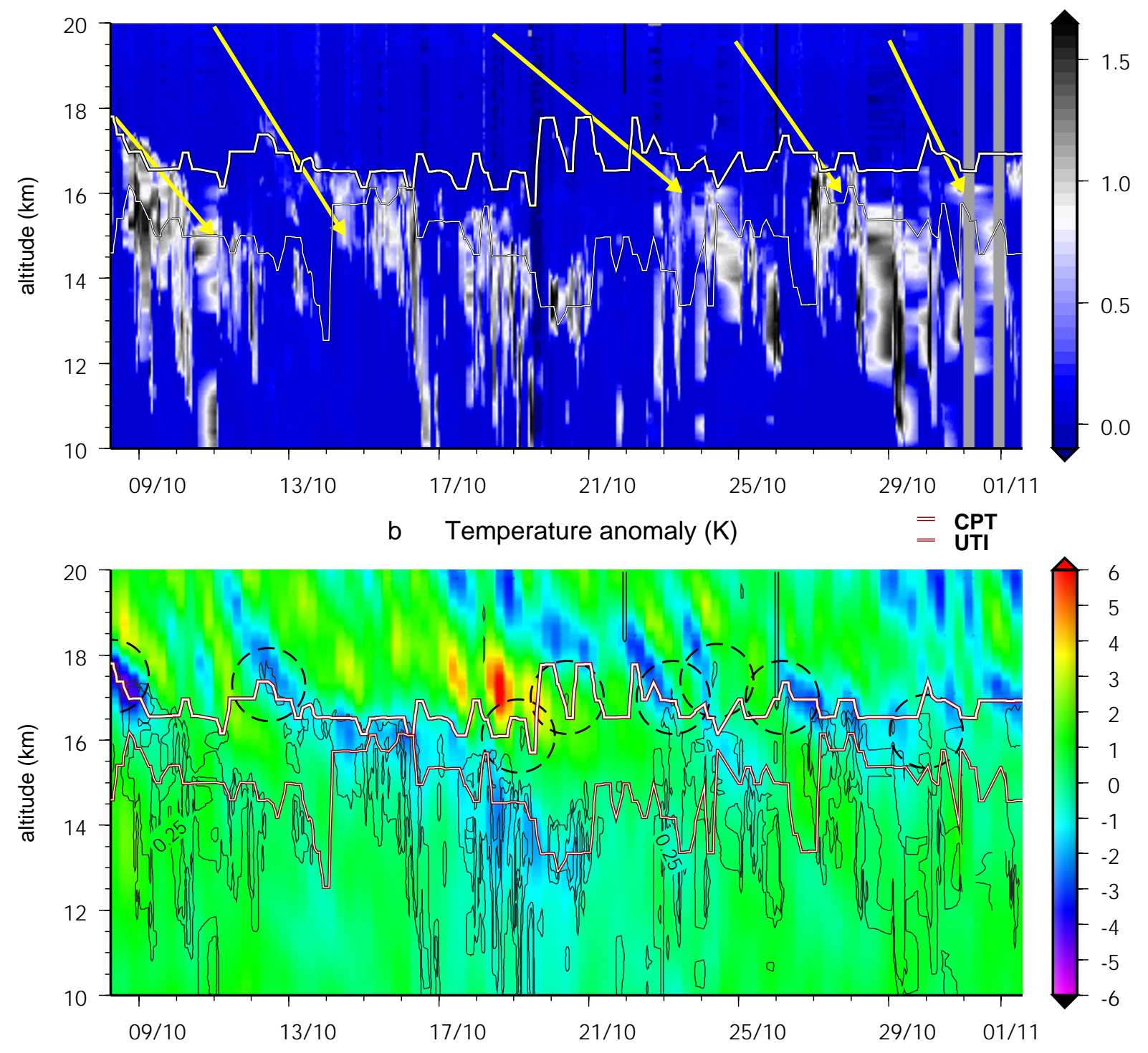

day

Fig. 3. Same as Fig. 1 but for the ACLIT period, from 8 October to 1 November 2006. The temperature anomalies in (b) are retrieved from opECMWF data at $6.0^{\circ} \mathrm{N}, 56^{\circ} \mathrm{W}$.

equatorial Kelvin waves, that were likely to have been caused by remote convective systems. The shorter periodicity observed in the lower stratosphere, sometimes down to 4 days, resembles that in the case reported by Holton et al. (2001) in the western Pacific.

The temperature changes at the CPT induced by the waves reach amplitudes of up to $8 \mathrm{~K}$ with typical values of $2-3 \mathrm{~K}$. The cirrus clouds observed by the lidar (Fig. 1a) are indicated by contour lines in Fig. $1 \mathrm{~b}$ in order to show the correlation between the cold temperature anomalies and the occurrence of ice particles. Clearly, clouds in the TTL occur almost exclu- sively in regions with a cold anomaly, while warm anomalies inhibit cloud formation.

For the ACLIT period in October 2006 the temperature anomalies were retrieved from the high vertical-resolution version of the opECMWF analysis with 91 model levels (Fig. 3b), which became operational since 1. February 2006. We see the same downward phase propagating features. In an analoguous way to the STAR case, we can demonstrate that the temperature anomalies are caused by equatorial Kelvin waves. Again, there is a strong correlation between the cold phases in the TTL and the occurrence of cirrus. 


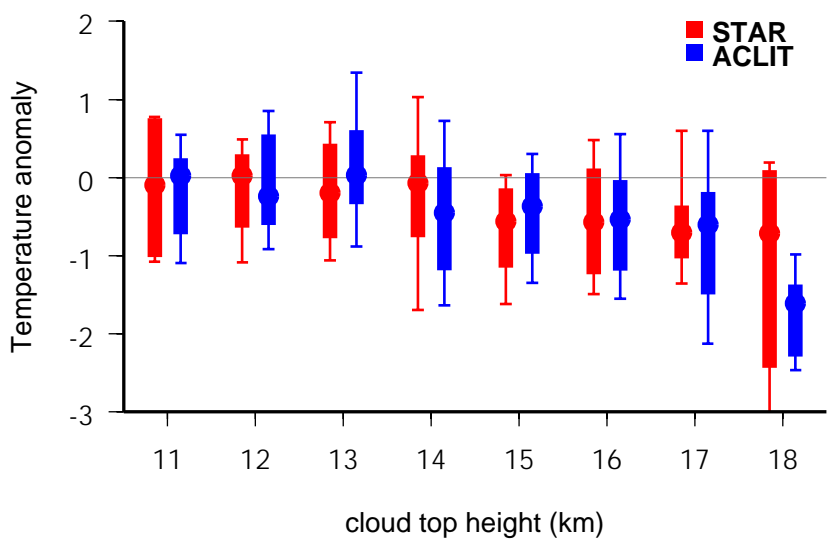

Fig. 4. In-cloud temperature anomaly as a function of cloud top height retrieved from lidar and collocated radiosonde or the opECMWF data for the STAR (red) and ACLIT (blue) periods, respectively. The dots mark the median, the box the $75 \%$ and $25 \%$ quartiles, and the error bars mark the $10 \%$ and $90 \%$-percentiles within a $1 \mathrm{~km}$ wide altitude bin.

The CPT follows the descending cold anomalies to some extent until it rises rapidly when a new cold anomaly appears at an altitude of about $17-18 \mathrm{~km}$ (Figs. $1 \mathrm{~b}$ and $3 \mathrm{~b}$ ). At this newly formed CPT we find regularly extremely thin cirrus clouds. The occurrence of these thin clouds are marked with black dashed circles in Figs. $1 b$ and $3 b$.

Figure 4 is a compilation of the temperature anomalies as shown in Figs. $1 \mathrm{~b}$ and $3 \mathrm{~b}$ averaged over the cloud range for each cloud event detected by the lidar during the entire campaigns. Clouds above $15.5 \mathrm{~km}$ occur almost exclusively in cold anomalies, proving that thin ice clouds that occur near the tropical tropopause are closely correlated with Kelvin waves. A "stratospheric influence" on cloud formation in the TTL (below 15-16 km) was demonstrated by Boehm and Verlinde (2000) and Comstock et al. (2002). However, in contrast to their findings, we find this correlation to increase with cloud top altitude. The reason for this discrepancy may be that our lidar systems are sensitive to extremely thin clouds while the one used in those studies is not.

In order to show a detailed case of an extremely thin cloud occurring at the CPT, the temperature and temperature anomaly profiles are plotted in Fig. 5a which were measured on 11 October 2004, 08:26 UT. The temperature profile has a double tropopause structure with a significant lapse rate change at $16.5 \mathrm{~km}$ and a minimum at $17.2 \mathrm{~km}$. This is typical for the situation when the cold phase of Kelvin waves approaches the tropopause region. The upper temperature minimum at $17.2 \mathrm{~km}$ altitude is clearly related to a downward propagating cold anomaly that reaches the TTL at the time of the observation (see the vertical gray arrow in Fig. 1b). The temperature profile in Fig. 5a shows a lower lapse rate tropopause at about $16.5 \mathrm{~km}$ altitude. The thermal structure of the TTL is obviously strongly influenced by the Kelvin wave and so is the existence of ice clouds, in particular the upper cloud layer at the temperature minimum (Fig. 5b).

This relation is investigated in more detail with the help of backward trajectories which were calculated with the AWI trajectory code that was used for our previous study in $\mathrm{I} 07$ and Krüger et al. (2008). The thin red line in Fig. 5c depicts the history of the potential temperature of the air parcel that contains the upper cloud of Fig. 5b. This air was transported into the TTL about 8 days before. In the TTL the air slowly ascends (increasing potential temperature), while the temperature (thick lines) at that stage shows no clear trend. Later, the air was cooled by about $5 \mathrm{~K}$ (see the thick red line) which is presumably caused by the Kelvin wave. The dynamical cooling by the Kelvin wave let the temperatures drop below the point of radiative equilibrium and leads to enhanced radiative heating which rises by $50 \%$ to $100 \%$ compared to mean values that are typical for this altitude range (Fueglistaler and $\mathrm{Fu}, 2006$ ). This is reflected by an increasing slope of the potential temperature (Fig. $5 \mathrm{c}$, thin red line). This process is supported by the formation of ice clouds and "cloud lofting" as described by Corti et al. (2006) which will further enforce radiative heating and ascent. The cooling of the tropopause brought about by Kelvin waves thus lead to enhanced ascent, cloud formation, and dehydration of the TTL. This is clearly demonstrated by our observations (Figs. 1 and 3).

The case depicted in Fig. 5 suggests that the extremely thin cloud at about $17 \mathrm{~km}$ altitude is generated primarily by the Kelvin wave disturbance. There is no other disturbance noticeable from the potential temperature history. This is supported by the regular observation of extremely thin clouds at the CPT during the cold phases of Kelvin waves (circles in Figs. $1 b$ and $3 b$ ). The forward trajectory in Fig. 5c (thin red line to the right of zero) shows that after the cloud had formed the air parcel climbs up to $380 \mathrm{~K}$ and thus enters the stratosphere. The extremely thin ice cloud that we have observed was the last dehydration event that the air encountered and therefore plays a crucial role for determining the water vapor content of this stratospheric air parcel.

Our observations are restricted to areas outside of deep convection by the nature of the lidar measurements which can only be performed during the absence of low and mid level clouds. Therefore, our conclusions apply only to regions which are not directly affected by deep convection. However most of the vertical transport from the troposphere to the stratosphere is obviously not directly related to convection: we have repeatedly observed high coverage with thin cirrus in the TTL detached from deep convection (I07, Immler and Schrems, 2002) which seems to be the case for the great majority of TTL cirrus. Satellite observations demonstrated that $90 \%$ of the tenuous cirrus near the tropopause is located away from deep convection (Massie et al., 2002). 


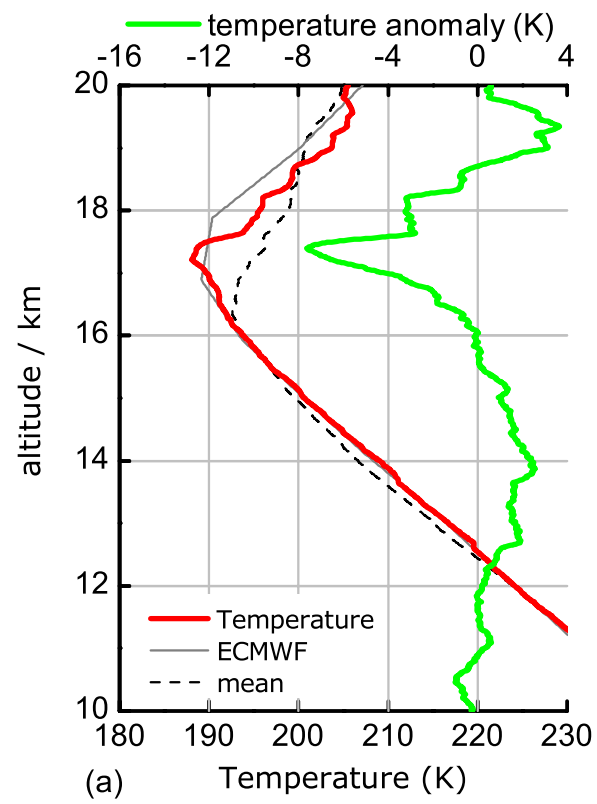

11.10.2004 08:26:00

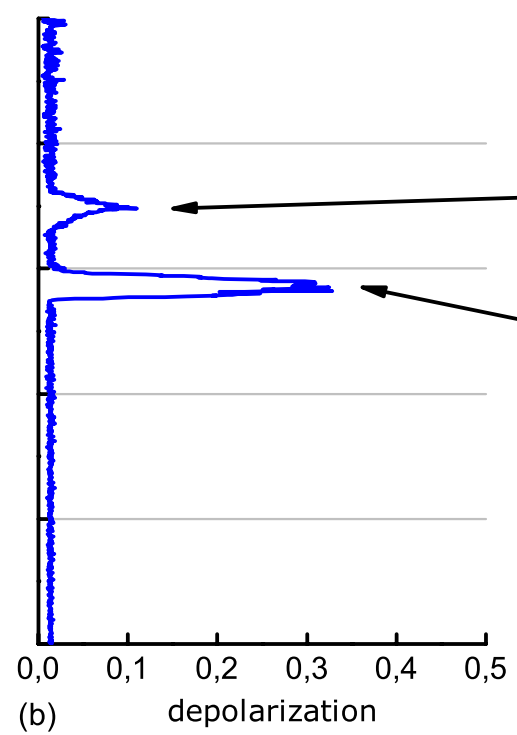

$\mathrm{T}(\mathrm{K}) \quad$ backward trajectories

$\Theta(K)$

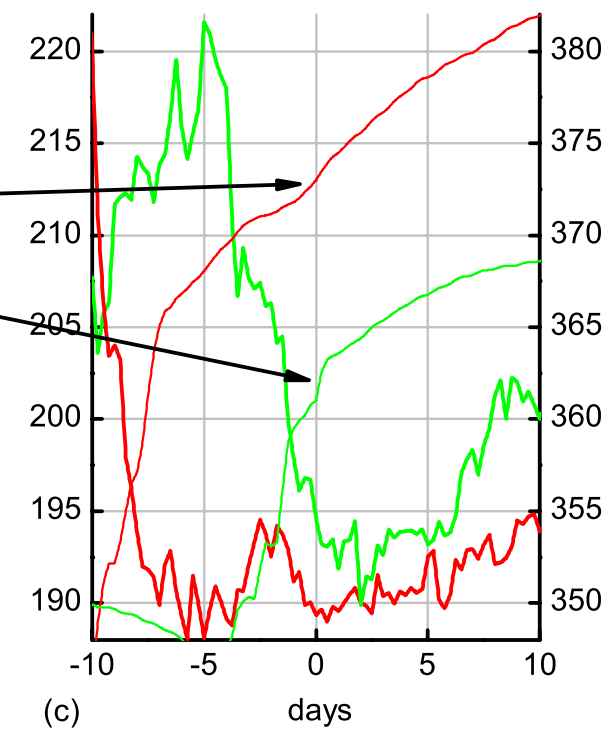

Fig. 5. (a) Profiles of temperature measured by a radiosonde launched on 11 October 2004, 10:16 UT (red), temperature from the opECMWF data on the same day but at 06:00 UT (gray), mean temperature during the STAR period (dashed), and temperature anomaly (green). (b) Lidar backscatter profile measured between 08:07 and 08:26 UT. (c) Backward and forward trajectories calculated from 11 October 2004 06:00 UT from two different levels. Thick lines show the temperature history of the air parcels, and thin lines show their potential temperature history. The green lines refer to the air parcel containing the cloud around $15.8 \mathrm{~km}$, while the red lines refer to the air parcel containing a very thin cloud at about $17 \mathrm{~km}$.

\section{Conclusions}

The correlation of cloud observations by lidar with temperature anomalies determined from radiosonde measurements or opECMWF analysis demonstrates that cirrus occurrence in the tropical tropopause region is closely related to equatorial Kelvin waves. The downward propagating cold anomalies obviously provide favorable synoptic-scale conditions in the TTL for enforced ascent and adiabatic cooling of air parcels followed by ice particle formation and dehydration. The absorption of long wave radiation by the ice clouds and subsequent "cloud lofting" (Corti et al., 2006) provides a positive feedback mechanism that may significantly enhance this process.

As Boehm and Verlinde (2000) have pointed out, the temperature anomalies caused by waves modulate the thermal structure of the tropical tropopause region and support the creation of a very cold secondary tropopause around $17 \mathrm{~km}$ above the conventional lapse rate tropopause (or UTI around $15 \mathrm{~km}$ ). However, they did not establish a correlation to the formation of clouds at the upper part of the TTL probably due to a limited ability of their instrument to detect the extremely tenuous clouds. Our observations demonstrate that extremely thin clouds occur regularly around 17 to $18 \mathrm{~km}$ when a particularly high tropopause coincides with the cold phase of a Kelvin wave.
These observations suggest that the level of water vapour flux into the stratosphere depends on the degree of Kelvin wave activity, with higher wave activity leading to stronger dehydration and a drier lowermost stratosphere in the tropics. Should the intensity of Kelvin wave activity change in a changing climate, this could link anthropogenic climate forcings with stratospheric water vapour levels, with all its global implications.

Acknowledgements. We like to thank Ingo Beninga, David Kaiser, and Raffael Maurer for operating the lidar systems in Paramaribo, as well as Cor Becker and his staff from the Meteorologische Dienst Suriname for their great support. We thank the ECMWF for giving access to their data. We greatly acknowledge financial support by the EU projects STAR, ACCENT, and SCOUT-O3 as well as by the Helmholtz Association within the virtual institute PEP. Also, we like to thank the editor Peter Haynes and three anonymous referees for carefully reviewing the manuscript and helpful comments and corrections.

Edited by: P. Haynes 


\section{References}

Boehm, M. and Verlinde, J.: Stratospheric influence on upper tropospheric tropical cirrus, Geophys. Res. Lett., 27, 3209-3212, doi:2000GL011678, 2000.

Bonazzola, M. and Haynes, P. H.: A trajectory-based study of the tropical tropopause region, J. Geophys. Res., 109, D20 112, doi: 10.1029/2003JD004356, 2004.

Comstock, J. M., Ackerman, T. P., and Mace, G. G.: Ground-based lidar and radar remote sensing of tropical cirrus clouds at Nauru Island: Cloud statistics and radiative impacts, J. Geophys. Res., 107, 4714, doi:10.1029/2002JD002203, 2002.

Corti, T., Luo, B. P., Fu, Q., Vömel, H., and Peter, T.: The impact of cirrus clouds on tropical troposphere-to-stratosphere transport, Atmos. Chem. Phys., 6, 2539-2547, 2006,

http://www.atmos-chem-phys.net/6/2539/2006/.

Fueglistaler, S. and $\mathrm{Fu}, \mathrm{Q}$.: Impact of clouds on radiative heating rates in the tropical lower stratosphere, J. Geophys. Res., 111, D23 202, doi:10.1029/2006JD007273, 2006.

Fueglistaler, S., Bonazzola, M., Haynes, P. H., and Peter, T.: Stratospheric water vapor predicted from the Lagrangian temperature history of air entering the stratosphere in the tropics, J. Geophys. Res., 110, D08 107, doi:10.1029/2004JD005516, 2005.

Fujiwara, M., Hasebe, F., Shiotani, M., Nishi, N., Vömel, H., and Oltmans, S. J.: Water vapor control at the tropopause by equatorial Kelvin waves observed over the Galápagos, Geophys. Res. Lett., 28, 3143-3146, doi:10.1029/2001GL013310, 2001.

Fujiwara, M., Xie, S.-P., Shiotani, M., Hashizume, H., Hasebe, F., Vömel, H., Oltmans, S. J., and Watanabe, T.: Upper-tropospheric inversion and easterly jet in the tropics, J. Geophys. Res., 108, 4796, doi:10.1029/2003JD003928, 2003.

Holton, J. R., Alexander, M. J., and Boehm, M. T.: Evidence for short vertical wavelength Kelvin waves in the department of energy-atmospheric radiation measurement Nauru99 radiosonde data, J. Geophys. Res., 106, 20 125-20 130, doi: 10.1029/2001JD900108, 2001.

Immler, F. and Schrems, O.: Determination of tropical cirrus properties by simultaneous LIDAR and radiosonde measurements, Geophys. Res. Lett., 29, 2090, doi:10.1029/2002GL015076, 2002.

Immler, F., Beninga, I., Ruhe, W., Stein, B., Mielke, B., Rutz, S., Terli, O., and Schrems, O.: A new LIDAR system for the detection of Cloud and aerosol backscatter, depolarization, extinction, and fluorescence, Reviewed and revised papers presented at the 23rd International Laser Radar Converence, 24-28 July 2006, I, pp. 35-38, 2006.
Immler, F., Krüger, K., Tegtmeier, S., Fujiwara, M., Fortuin, P., Verver, G., and Schrems, O.: Cirrus clouds, humidity, and dehydration in the tropical tropopause layer observed at Paramaribo, Suriname $\left(5.8^{\circ} \mathrm{N}, 55.2^{\circ} \mathrm{W}\right)$, J. Geophys. Res., 112, D03 209, doi:10.1029/2006JD007440, 2007.

Jensen, E. and Pfister, L.: Transport and freeze-drying in the tropical tropopause layer, J. Geophys. Res., 109, D02 207, doi: 10.1029/2003JD004022, 2004.

Krüger, K., Tegtmeier, S., and Rex, M.: Long-term climatology of air mass transport through the Tropical Tropopause Layer (TTL) during NH winter, Atmos. Chem. Phys., 8, 813-823, 2008, http://www.atmos-chem-phys.net/8/813/2008/.

Luo, B., Peter, T., Fueglistaler, S., Wernli, H., Wirth, M., Kiemle, C., Flentje, H., Yushkov, V. A., Khattatov, V., Rudakov, V., Thomas, A., Borrmann, S., Toci, G., Mazzinghi, P., Beuermann, J., Schiller, C., Cairo, F., Donfrancesco, G. D., Adriani, A., Volk, C. M., Ström, J., Noone, K., Mitev, V., MacKenzie, R. A., Carslaw, K. S., Trautmann, T., Santacesaria, V., and Stefanutti, L.: Dehydration potential of ultrathin clouds at the tropical tropopause, Geophys. Res. Lett., 30, 1557, doi: 10.1029/2002GL016737, 2003.

Massie, S., Gettelman, A., Randel, W., and Baumgardner, D.: Distribution of tropical cirrus in relation to convection, Rev. Geophys., 107, 4591, doi:10.1029/2001JD001293, 2002.

Nielsen, J. K., Larsen, N., Cairo, F., di Donfrancesco, G., Rosen, J. M., Durry, G., Held, G., and Pommereau, J. P.: Solid particles in the tropical lowest stratosphere, Atmos. Chem. Phys., 7, 685695, 2007, http://www.atmos-chem-phys.net/7/685/2007/.

Parker, D.: Equatorial Kelvin waves at 100 millibars, Quarterly Journal of the Royal Meteorological Society, 99, 116-129, doi: 10.1256/smsqj.41909, 1973.

Peter, T., Luo, B. P., Wirth, M., Kiemle, C., Flentje, H., Yushkov, V. A., Khattatov, V., Rudakov, V., Thomas, A., Borrmann, S., Toci, G., Mazzinghi, P., Beuermann, J., Schiller, C., Cairo, F., di Donfrancesco, G., Adriani, A., Volk, C. M., Ström, J., Noone, K., Mitev, V., MacKenzie, R. A., Carslaw, K. S., Trautmann, T., Santacesaria, V., and Stefanutti, L.: Ultrathin Tropical Tropopause Clouds (UTTCs): I. Cloud morphology and occurrence, Atmos. Chem. Phys., 3, 1083-1091, 2003, http://www.atmos-chem-phys.net/3/1083/2003/.

Winker, D. and Trepte, C.: Laminar cirrus observed near the tropical tropopause by LITE, Geophys. Res. Lett., 25, 3351-3354, 1998. 